\title{
MATERNAL NEAR MISS IN A TERTIARY CARE HOSPITAL: A CROSS SECTIONAL STUDY
}

\author{
Namrata Ray1, Sanjay Kumar Patil2, Nitin S. Kshirsagar³, Yaminni Patil4, Manisha Laddad5 \\ ${ }_{1}^{1}$ Resident, Department of Obstetrics and Gynaecology, Krishna Institute of Medical Sciences, Karad. \\ ${ }^{2}$ Professor, Department of Obstetrics and Gynaecology, Krishna Institute of Medical Sciences, Karad. \\ 3 Professor, Department of Obstetrics and Gynaecology, Krishna Institute of Medical Sciences, Karad. \\ ${ }^{4}$ Associate Professor, Department of Obstetrics and Gynaecology, Krishna Institute of Medical Sciences, Karad. \\ ${ }^{5}$ Associate Professor, Department of Obstetrics and Gynaecology, Krishna Institute of Medical Sciences, Karad.
}

\section{ABSTRACT}

\section{BACKGROUND}

Maternal mortality is one of the important indicators of maternal health. To overcome the challenge of reduction of maternal mortality, nationwide notion of SAMM (Severe Acute Maternal Morbidity) and near miss event was introduced to access maternal health care. Maternal near miss case is defined as "A woman who nearly died, but survived a complication that occurred during pregnancy, childbirth or within 42 days of termination of pregnancy." SAMM refers to a life-threatening disorder that can end up in near miss with or without residual morbidity or mortality. Women who develop SAMM during pregnancy share many pathological and circumstantial factors related to their condition. Although some of these women die, a proportion of them narrowly escape death. Near miss cases and maternal deaths together are referred to as Severe Maternal Outcome (SMO).

\section{AIMS AND OBJECTIVES}

1. To determine the prevalence of maternal near miss due to severe obstetric complications or maternal disease in a tertiary hospital.

2. To determine Severe Maternal Outcome Ratio (SMOR), Maternal Near Miss Ratio (MNM Ratio) and Maternal Mortality Ratio.

\section{MATERIALS AND METHODS}

Cross sectional observational study carried out from 01st October 2014 to $30^{\text {th }}$ September 2015. The study was conducted in Obstetric Department of Krishna Hospital, Krishna Institute of Medical Sciences Deemed University, Karad. Near-miss case definition was based on validated specific criteria comprising of five diagnostic features and WHO Criteria: Haemorrhage, hypertensive disorders in pregnancy, dystocia, infection and anaemia. The main outcome measures were frequency and characteristics of nearmiss cases, total hospital stay, high dependency unit/ICU stay and development of multiple organ dysfunction. The maternal death to near-miss ratio was calculated.

\section{RESULT}

There were 4800 deliveries from October 2014 to September 2015, 220 near miss cases and 17 maternal deaths. Maternal death to near miss ratio was 1:15. The most common type of near miss events were severe hypertensive disorders of pregnancy, obstetrical haemorrhage, ectopic pregnancy and anaemia responsible for 56\%, 11\%, 7\%, 6\% respectively. Other causes were traumatic PPH, organ system dysfunction and obstructed labour and infections.

\section{CONCLUSION}

This study showed that for every 15 women who survived life-threatening conditions one died. Hence, evaluation of surrounding near miss cases could act as a proxy for maternal deaths in the studied population. This will go a long way improving maternal health and reducing maternal mortality.

\section{KEYWORDS}

MD: Maternal Death, MNMR: Maternal Near Miss Incidence Ratio, MI: Mortality Index, MMR: Maternal Mortality Ratio, SAMM: Severe Acute Maternal Morbidity.

HOW TO CITE THIS ARTICLE: Ray N, Patil SK, Kshirsagar NS, et al. Maternal near miss in a tertiary care hospital: a cross sectional study. J. Evolution Med. Dent. Sci. 2016;5(51):3252-3254, DOI: 10.14260/jemds/2016/755

\section{INTRODUCTION \\ The status of women and their health care system can be assessed by a country's maternal mortality ratio. For many years, evaluation of maternal healthcare services aimed at improving the quality of obstetric care has traditionally relied on enquiries into maternal deaths.}

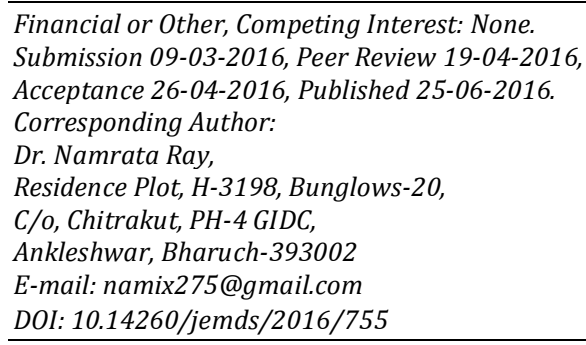

More recently, review of cases at the very severe end of the maternal morbidity spectrum, described as "Near-Miss" (Those who nearly died), has been found to be a useful complement to investigation of maternal mortality.[1,2] Maternal near miss is said to be occurred when women presented with life threatening complication during pregnancy, child birth and within 42 days after delivery, but survive by chance or good institutional care. Currently maternal near-miss ratio is increasingly used to evaluate the quality of obstetric care in low income countries.[3] A nearmiss case is a woman with at least one near-miss event. Nearmiss cases occur more often than maternal deaths and may generate more information, because the woman herself can be a source of data.

Once maternal morbidity precedes maternal death, the systematic identification and the study of near-miss cases 
helps in further understanding the determinants of maternal mortality. ${ }^{[4,5]}$ A more comprehensive and statistically reliable quantitative analysis that is of value to clinical audit can be rapidly conducted.[1,2,6,7] This study was conducted to determine the prevalence of near-miss cases and the nature of near-miss events and mortalities among the obstetric patients in order to serve as a complementary method for auditing the quality of maternal health care in our institution.

\section{METHODOLOGY}

This was a cross-sectional observational study carried out from 1 October 2014 to 30 September 2015 in Obstetric Department of Krishna Hospital, Krishna Institute of Medical Sciences Deemed University, Karad. The hospital serves the lower socio-economic community of Western Maharashtra including villages. It is also a referral centre for nearby small clinics and maternity hospitals, which provides 24-hour antenatal care and delivery services for both low and high risk pregnant women and special services for high risk obstetric cases.

Among all cases, potentially life-threatening conditions were diagnosed and those cases which met WHO 2009 criteria for near miss were selected. WHO criteria included a set of clinical, laboratory and management-based criteria. ${ }^{[3]}$ Maternal mortality during the same period was also analysed. Patient characteristics including age, parity, gestational age at admission, booked.[8] (More than three antenatal visits to our hospital irrespective of the gestational age), mode of delivery, ICU admission, duration of ICU stay, total hospital duration and surgical intervention to save the life of mother were considered. Patients were categorized by final diagnosis with respect to haemorrhage, hypertension, sepsis, dystocia (Direct Causes). Anaemia, thrombocytopenia and other medical disorders were considered as indirect causes contributing to maternal near miss and deaths.

Near-miss cases were identified among women with pregnancy-related complications whose diagnosis met the above mentioned criteria and who were admitted in the obstetric unit of Krishna Hospital. Investigations were done for coagulation defects, septicaemia, anaemia and organ system dysfunction/failure.

Data was collected for determining the nature of the obstetrical complication, presence of organ-system dysfunction/failure and timing of near miss events with respect to admission. Foetal outcome and ICU admissions were also noted. Detailed information of maternal mortalities for the underlying cause and time period was obtained.

The descriptive analysis of collected data was done and the results were given in percentages. The frequency of nearmiss cases and maternal death to near-miss ratio was calculated. Mortality indices were determined for various disease processes to appreciate the standard of care provided for life-threatening obstetric conditions.

\section{RESULTS}

During the period of audit there were a total of 4583 deliveries and 4038 live births, 220 near-miss cases and 17 maternal deaths, 169 live births in near miss.

\begin{tabular}{|c|c|c|}
\hline Characteristics & $\begin{array}{c}\text { Near Miss } \\
\text { (n=220) }\end{array}$ & $\begin{array}{c}\text { Maternal Death } \\
\text { (n=17) }\end{array}$ \\
\hline Age & $26.4 \pm 4.5$ & $27 \pm 4.8$ \\
\hline Parity & & \\
Primipara & $120(54.4 \%)$ & $10(58.3 \%)$ \\
Multipara & $100(45.6 \%)$ & $7(41.6 \%)$ \\
\hline Gestational Age & $28(12.7 \%)$ & 0 \\
$1-12$ & $29(13 \%)$ & 0 \\
$13-28$ & $137(62.4 \%)$ & $12(70.6 \%)$ \\
$>28$ & $26(11.8 \%)$ & $5(29.4 \%)$ \\
Postnatal & $85(38.6 \%)$ & $4(23.5 \%)$ \\
Causes & $89(40.3 \%)$ & $1(5.8 \%)$ \\
Haemorrhage & $3(1.36 \%)$ & $4(23.5 \%)$ \\
Hypertension & $12(2.9 \%)$ & $3(17.6 \%)$ \\
Sepsis & $11(5 \%)$ & $3(17.6 \%)$ \\
Cardiac & $15(6.7 \%)$ & $2(11.8 \%)$ \\
Indirect & Anaemia & \multicolumn{2}{|c|}{ Table 1: Shows the Characteristics of Women } \\
\multicolumn{2}{|c|}{ with Near Miss and Mortality } \\
\hline
\end{tabular}

Primiparas were slightly more in the near-miss group. Majority of the patients (62.4\%) were in third trimester at a near-miss event, whereas in the maternal death group the number of postnatal patients with haemorrhage and sepsis were more. A huge burden of maternal near-miss cases, $85 \%$ were referred from government setup and private health institutions. A total of 413 potentially life-threatening conditions were identified of which 220 were near-miss cases. Maternal near-miss to mortality ratio is $13: 1$. The mortality index is $7.17 \%$. A total of $62.6 \%$ of the cases required ICU admission. Among the causes of near-miss events, hypertension was the leading cause with $40.3 \%$ and haemorrhage was $38.6 \%$. Third among the group was anaemia, cardiac and other indirect causes. Haemorrhage and sepsis were the leading cause of maternal mortality at our setup followed by cardiac disease, anaemia and hypertension. We had 3 cases of H1N1 infection with ARDS. This accounted for the high mortality due to sepsis.

\section{DISCUSSION}

Obstetric deaths represent the quality of maternal care. But for the present scenario, it may not reflect the global situation with regard to obstetric care. Hence, new "near miss" criteria took over maternal mortality ratio. Although near-miss criteria were in vogue for some years, lack of uniformity was the hindrance. WHO criteria, 2009.[3] are unique in considering not only clinical but also laboratory and management-based criteria. Hence, it incorporates both Mantel's.[9] and Waterston's criteria.[10] So if one of the criteria fails to pick the case the other makes it up, thus minimizing the chance of missing the case. According to WHO bulletin 2010, the study of secondary analysis of WHO global survey on Latin America described near-miss in 120 institutions and recorded MMR 15:1.[11] Souza et al, in a current demographic health survey reported MNM prevalence as 21.3/1000 live births in Brazil.[11]

Compared with them, MNM prevalence of 54.4/1000 live births in our study is low, while the maternal deaths to nearmiss rate of 1:13 is high indicating that there is a high rate of maternal mortality in the developing countries. The Maternal Near-Miss Incidence Ratio (MNMR) was 54/1000 live births in our hospital. 
Studies done in the developing countries showed the same trend and vary from anywhere between 15-40/1000 live births. ${ }^{[12,13]}$ The above studies have used various criteria for identification of the cases. The near miss-to-mortality ratio was $13: 1$, which means for every thirteen life-threatening conditions there was one maternal death. Higher ratios indicate better care. Syrian study showed a ratio of $60: 1$ and study done in Nepal showed a ratio of 7.2:1.[13,14] A study done by P Kalra et al in western Rajasthan showed a ratio of 1:2.07, which was extremely high.[15] This ratio is similar to those of African country, where the range is 1:5-12.[13] This is a far cry from those reported in Western Europe. Their studies have reported a ratio of 117-223:1.[16] If this ratio increases over a period of time, it reflects on the improvement achieved in obstetric care. So instead of a single estimation, yearly estimation may help us in improving the care provided.

The maternal mortality ratio at our setup was $421 / 100000$ live births. The Brazilian study showed a similar mortality rate of 260/100000 live births.[13] In other developing countries, the maternal mortality ratios were $423 / 100000$ live births and $324 / 100000$ live births.[14,17] Sepsis is on the rise due to epidemics of viral infections. The leading cause was postpartum haemorrhage and sepsis followed by cardiac causes. The cases that were referred were in an already exsanguinated state. Though we have $24 \mathrm{hrs}$. working blood bank with cell separator hence component therapy, we were not able to revive these untimely referred cases. One death was due to complication of hypertension.

\section{ABBREVIATIONS}

\begin{tabular}{|c|c|}
\hline MD & Maternal Death \\
\hline MNMR & Maternal Near Miss Incidence Ratio \\
\hline MI & Mortality Index \\
\hline MMR & Maternal Mortality Ratio \\
\hline SAMM & Severe Acute Maternal Morbidity \\
\hline
\end{tabular}

\section{CONCLUSION}

Hypertension and Haemorrhage are the leading causes of near-miss events. New onset viral infections like H1N1 have emerged as one of the leading causes of maternal mortality. As near-miss analysis indicates quality of health care, it is worth presenting in national indices.

\section{REFERENCES}

1. Ronsmans C, Filippi V. Reviewing severe maternal morbidity: learning from survivors from life-threatening complications. In beyond the numbers: reviewing deaths and complications to make pregnancy safer geneva: World Health Organization, 2004;103-24.

2. Pattinson RC, Buchmann E, Mantel G, et al. Can enquiries into severe acute maternal morbidity act as a surrogate for maternal death enquiries? BJOG 2003;110(10):889-93.
3. WHO. Evaluating the quality of care for severe pregnancy complications: the WHO near miss approach for maternal health. World Health Organization 2011.

4. Stones W, Lim W, Al-Azzawi F, et al. An investigation of maternal morbidity with identification of life-threatening near miss episodes. Health Trends 1991;23(1):13-5.

5. Pattinson RC, Hall M. Near-misses: a useful adjunct to maternal death enquiries. Br Med Bull 2003;67:231-43.

6. Cochet L, Pattinson RC, Macdonald AP. Severe acute maternal morbidity and maternal death audit: a rapid diagnostic tool for evaluating maternal care. S Afr Med J 2003;93(9):700-2.

7. Vandecruys HIB, Pattinson RC, Macdonald AP, et al. Severe acute maternal morbidity and mortality in the pretoria academic complex: changing patterns over 4 years. Eur J Obstet Gynaecol Reprod Biol 2002;102(1):6-10.

8. Park K. Text book of preventive and social medicine, banarsidas bhanot, Jabalpur, India, 2015;23 rd ed.

9. Mantel GD, Buchmann E, Rees H, et al. Severe acute maternal morbidity: a pilot study of a definition for a nearmiss. British Journal of Obstetrics and Gynaecology 1998;105(9):985-90.

10. Waterstone M, Wolfe C, Bewley S. Incidence and predictors of severe obstetric morbidity: case-control study. British Medical Journal 2001;322(7294):1089-93.

11. Souza JP, Cecatti JG, Faundes A, et al. Maternal near miss and maternal death in the World Health Organization's 2005 global survey on maternal and perinatal health. Bull World Health Organ 2010;88:113-9.

12. Souza JP, Cecatti JG, Parpinelli MA, et al. Appropriate criteria for identification of near-miss maternal morbidity in tertiary care facilities: a cross sectional study. BMC Pregnancy and Childbirth 2007;7(20):1-8.

13. Prural A, Huguet D, Garbin 0 , et al. Severe obstetric morbidity of the third trimester, delivery and early puerperium in Niamey (Niger). African Journal of Reproductive Health 1998;2(1):10-9.

14. Almerie Y, Almerie MQ, Matar HE, et al. Obstetric near-miss and maternal mortality in maternity university hospital, Damascus, Syria: a retrospective study. BMC Pregnancy and Childbirth 2010;10(65):2-7.

15. Kalra P, Chetan P Kachhwaha. Obstetric near miss morbidity and maternal mortality in a tertiary care centre in western Rajasthan. Indian J Public Health 2014;58(3):199-201.

16. Shrestha NS, Saha R, Karki C. Near miss maternal morbidity and maternal mortality at Kathmandu medical college teaching hospital. Kathmandu University Medical Journal 2010;8(30):222-6.

17. Van Roosemalen J, Zwart J. Severe acute maternal morbidity in high income countries. Best Practice and Research: Clinical Obstetrics and Gynaecology 2009;23(3):297-304. 